\title{
Minimally-invasive versus transcatheter aortic valve implantation: systematic review with meta-analysis of propensity-matched studies
}

\author{
Mathew P. Doyle $\mathrm{e}^{1,2,3}$, Kei Woldendorp ${ }^{1,2,4}$, Martin $\mathrm{Ng}^{1,4}$, Michael P. Vallely ${ }^{5}$, Michael K. Wilson ${ }^{6}$, \\ Tristan D. Yan ${ }^{1,6,7}$, Paul G. Bannon ${ }^{1,2,4}$
}

${ }^{1}$ The Royal Prince Alfred Hospital, Sydney, Australia; ${ }^{2}$ The Baird Institute of Applied Heart and Lung Surgical Research, Sydney, Australia; ${ }^{3}$ University of Wollongong School of Medicine, Keiraville, Australia; ${ }^{4}$ The University of Sydney Medical School, Camperdown, Australia; ${ }^{5}$ Ohio State University Wexner Medical Centre, Columbus, USA; ${ }^{6}$ Macquarie University Hospital, Macquarie University, Sydney, Australia; ${ }^{7}$ Collaborative Research (CORE) Group, Macquarie University, Sydney, Australia

Contributions: (I) Conception and design: MP Doyle, K Woldendorp, TD Yan; (II) Administrative support: PG Bannon, MK Wilson, M Ng; (III) Provision of study materials or patients: None; (IV) Collection and assembly of data: MP Doyle, K Woldendorp, M Ng, MP Vallely; (V) Data analysis and interpretation: TD Yan, MK Wilson, MP Vallely, PG Bannon, M Ng; (VI) Manuscript writing: All authors; (VII) Final approval of manuscript: All authors.

Correspondence to: Dr. Mathew P. Doyle. c/o Cardiothoracic Surgical Unit, Royal Prince Alfred Hospital, Syndey, NSW, AUS, USA.

Email: mpd06@uowmail.edu.au.

Background: Minimally invasive aortic valve replacement (MiAVR) and transcatheter aortic valve implantation (TAVI) provide aortic valve replacement (AVR) by less invasive methods than conventional surgical AVR, by avoiding complete sternotomy. This study directly compares and analyses the available evidence for early outcomes between these two AVR methods.

Methods: Electronic databases were searched from inception until August 2019 for studies comparing MiAVR to TAVI, according to predefined search criteria. Propensity-matched studies with sufficient data were included in a meta-analysis.

Results: Eight studies with 9,744 patients were included in the quantitative analysis. Analysis of riskmatched patients showed no difference in early mortality (RR 0.76, 95\% CI, 0.37-1.54, P=0.44). MiAVR had a signal towards lower rate of postoperative stroke, although this did not reach statistical significance (OR 0.42, 95\% CI, 0.13-1.29, P=0.13). MiAVR had significantly lower rates of new pacemaker (PPM) requirement (OR 0.29, 95\% CI, 0.16-0.52, $\mathrm{P}<0.0001)$ and postoperative aortic insufficiency (AI) or paravalvular leak (PVL) (OR 0.05, 95\% CI, 0.01-0.20, $\mathrm{P}<0.0001)$ compared to TAVI, (OR 0.42, 95\% CI, 0.13-1.29, $\mathrm{P}=0.13$ ), while acute kidney injury (AKI) was higher in MiAVR compared to TAVI (11.1\% vs. 5.2\%, OR 2.28, 95\% CI, 1.25-4.16, P=0.007).

Conclusions: In patients of equivalent surgical risk scores, MiAVR may be performed with lower rates of postoperative PPM requirement and AI/PVL, higher rates of AKI and no statistical difference in postoperative stroke or short-term mortality, compared to TAVI. Further prospective trials are needed to validate these results.

Keywords: Minimally invasive; transcatheter aortic valve implantation (TAVI); aortic valve; transcatheter aortic valve replacement (TAVR); aortic valve replacement (AVR)

Submitted Jun 23, 2020. Accepted for publication Dec 24, 2020.

doi: $10.21037 /$ jtd-20-2233

View this article at: http://dx.doi.org/10.21037/jtd-20-2233 


\section{Introduction}

Aortic stenosis (AS) is one of the most common valvular pathologies, which progresses inexorably without intervention. Once symptoms develop, life-expectancy is significantly reduced unless the mechanical obstruction is relieved (1). While surgical aortic valve replacement (SAVR) has for decades been the gold standard in the treatment of severe AS, SAVR via full sternotomy confers significant risks, particularly to high-risk and frail patients. Although a full sternotomy provides excellent exposure of the heart and great vessels, some morbidity associated with SAVR may be mitigated using either alternate deployment routes or incisions.

Minimally invasive AVR (MiAVR) and transcatheter aortic valve implantation (TAVI) are two alternative AVR options, both which avoid full sternotomy. MiAVR can be performed via either a right anterior thoracotomy (RT) or a partial hemi-sternotomy (HS). MiAVR has shown reductions in pain, mechanical ventilation, blood transfusion requirement, sternal wound complications, atrial fibrillation and hospital length of stay (LOS) when compared to SAVR via complete sternotomy (2-5). The clinical applicability of MiAVR has expanded from low-risk patients into higher risk cohorts as improved postoperative outcomes have been demonstrated (6). TAVI can likewise be performed via several access routes, including femoral, axillary and carotid arteries. TAVI has demonstrated non-inferiority mortality outcomes in the short to medium term compared to SAVR in patients across all surgical risk categories (7-9), including low-risk surgical candidates in some continents following the results of large trials $(10,11)$.

The refinement of both MiAVR and TAVI techniques and the associated valve prostheses has facilitated the expansion of each procedure $(12,13)$. This has resulted in a higher number of patients with AS being concomitantly considered for either MiAVR or TAVI. While no prospective or randomised trial has been performed comparing MIAVR to TAVI, comparative data exists from a number of observational studies. We aim to review the literature for studies comparing MiAVR to TAVI and present a cohesive comparison in equivalent-risk patients who may be considered for either procedure. We present the following article in accordance with the PRISMA reporting checklist (available at http://dx.doi.org/10.21037/ jtd-20-2233).

\section{Methods}

\section{Search strategy and study selection}

Electronic searches were performed using Embase, PubMed, Cochrane central register of controlled trials and Web of Science, from their dates of inception until August 2019. The terms "aortic valve" and ("minimally-invasive", "mini", "hemi sternotomy" or "right thoracotomy") were combined with "transcatheter aortic valve", "TAVI" and "TAVR" as both keywords and MeSH terms. Two reviewers (MD and KW) independently screened the title and abstract of records identified in the search. Fulltext publications were subsequently reviewed separately if either reviewer considered the manuscript as potentially eligible for inclusion. Data was extracted independently by the reviewers. The reference lists of all retrieved articles were reviewed for further identification of potentially relevant studies. Only studies published in English were included. Studies were assessed for bias risk according to published criteria (14) (Figure 1).

\section{Inclusion criteria}

Eligible studies were those that compared TAVI against MiAVR in adult patients. All surgical approaches to MiAVR and all TAVI approaches were included. Where MiAVR

\begin{tabular}{|c|c|c|c|c|c|c|c|c|}
\hline Questions & $\begin{array}{l}\text { Study } 1 \\
\text { Zierer }\end{array}$ & $\begin{array}{l}\text { Study } 2 \\
\text { Tokarek }\end{array}$ & $\begin{array}{r}\text { Study } 3 \\
\text { Miceli }\end{array}$ & $\begin{array}{l}\text { Study } 4 \\
\text { Nguyen }\end{array}$ & $\begin{array}{l}\text { Study } 5 \\
\text { Terwelp }\end{array}$ & $\begin{array}{c}\text { Study } 6 \\
\text { Calle- } \\
\text { Valda }\end{array}$ & $\begin{array}{l}\text { Study } 7 \\
\text { Furukawa }\end{array}$ & $\begin{array}{l}\text { Study } 8 \\
\text { Paparella }\end{array}$ \\
\hline $\begin{array}{l}\text { Clear definition of study } \\
\text { population? }\end{array}$ & $\mathrm{Y}$ & $\mathrm{Y}$ & $\mathrm{Y}$ & $Y$ & $\mathrm{Y}$ & $Y$ & $\mathrm{Y}$ & Y \\
\hline $\begin{array}{l}\text { Clear definition of outcome and } \\
\text { outcome assessment? }\end{array}$ & Y & $Y$ & $\mathrm{Y}$ & $Y$ & Y & $Y$ & $Y$ & Y \\
\hline $\begin{array}{l}\text { Independent assessment of } \\
\text { outcome parameters? }\end{array}$ & unclear & $\mathrm{Y}$ & unclear & unclear & unclear & unclear & Y & unclear \\
\hline Sufficient duration of follow up? & $Y$ & Y & $Y$ & Y & $\mathrm{Y}$ & Y & Y & Y \\
\hline No selective loss during follow up? & $\mathrm{Y}$ & $\mathrm{N}$ & $\mathrm{Y}$ & unclear & unclear & $\mathrm{Y}$ & Y & $\mathrm{N}$ \\
\hline $\begin{array}{l}\text { Important confounders and } \\
\text { prognostic factors identified? }\end{array}$ & $\mathrm{Y}$ & $\mathrm{Y}$ & $\mathrm{Y}$ & $Y$ & $\mathrm{Y}$ & $\mathrm{N}$ & $Y$ & Y \\
\hline
\end{tabular}

Figure 1 Risk of bias assessment of all included studies, based on MOOSE guidelines. 


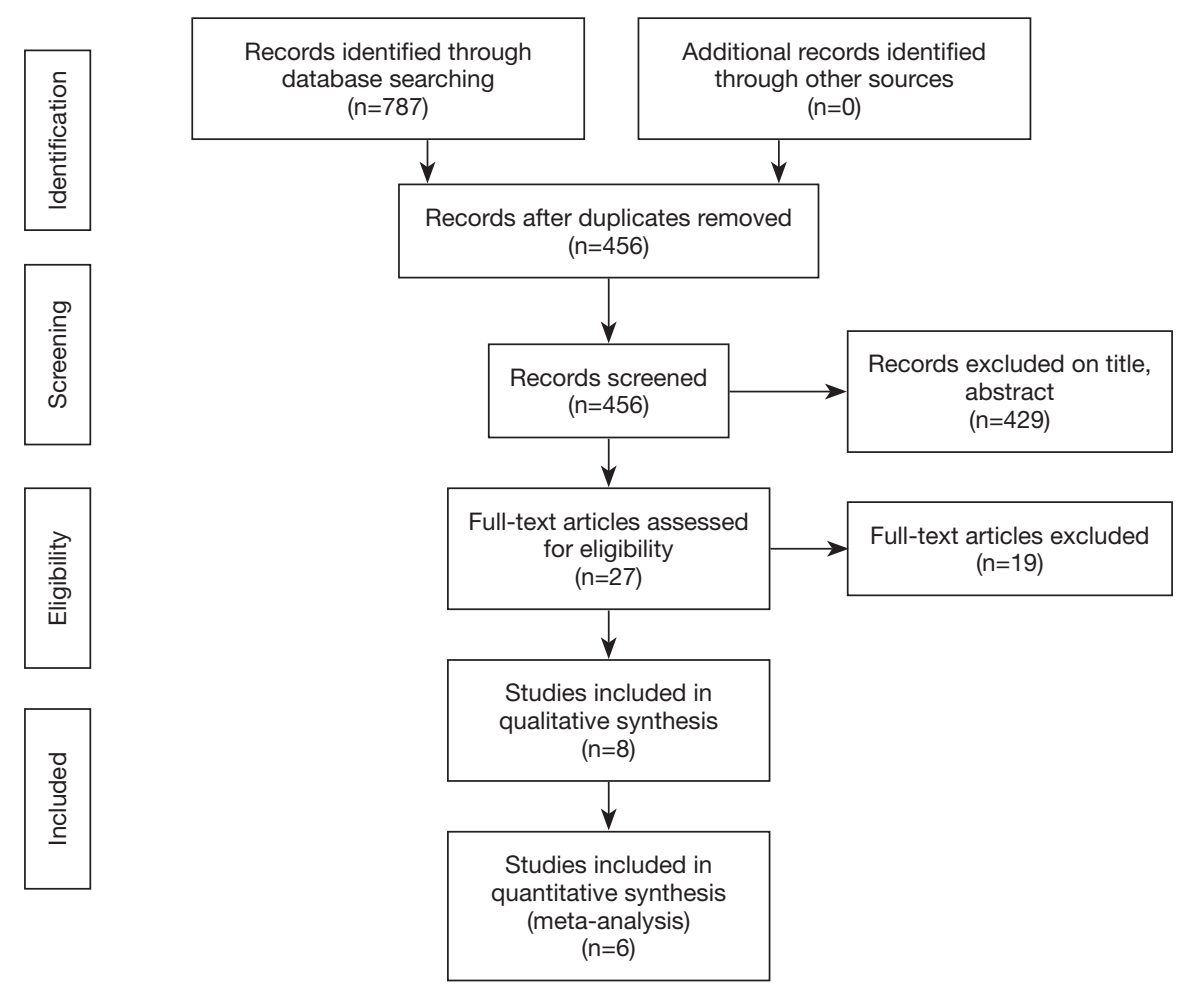

Figure 2 PRISMA flow chart summarizing the literature search strategy in the systematic review of MiAVR versus TAVI.

or TAVI results were reported separately according to approach, this data was collected separately and used for subgroup analysis.

\section{Study endpoints}

The primary endpoint was early mortality, defined as mortality within 30 days following the procedure. Secondary endpoints included stroke, postoperative aortic insufficiency (AI) of at least moderate severity, postoperative atrial fibrillation (POAF), permanent pacemaker (PPM) implantation, major bleeding, conversion to sternotomy, intensive care unit (ICU) length of stay (LOS), and hospital LOS.

\section{Analysis}

Baseline characteristics and intervention details were presented as raw values (\%) or mean \pm standard deviation unless otherwise indicated. Pooled values for baseline characteristics were reported as mean \pm standard deviation or as otherwise specified. Data were summarized as standard mean difference, with overall weighted mean presented where appropriate. $\mathrm{I}^{2}$ statistic was used to estimate the percentage of total variation across studies, due to heterogeneity rather than chance. An $\mathrm{I}^{2}$ value of greater than $50 \%$ was considered substantial heterogeneity. In the meta-analysis of risk-adjusted patients, results were calculated using a random-effects model. All $\mathrm{P}$ values were 2 -sided. A significant difference was defined as $\mathrm{P}<0.05$. Statistical analysis was conducted with Review Manager Version 5.3 (Cochrane Collaboration, Software Update, Oxford, UK).

\section{Results}

A total of 455 publications were identified through the database and bibliographic searches. The study selection process was performed as per the PRISMA statement (15) (Figure 2). After exclusion of duplicated or irrelevant publications, a total of eight studies totalling 9,744 patients were included and reviewed in detail (16-23) (Table 1). There were 5,774 patients who underwent MIAVR. A total of 149 patients had MiAVR via HS, 1,289 patients via RT and 4,336 patients had an unspecified approach. There were 3,970 patients who underwent TAVI, with 2,575 patients undergoing a trans-femoral approach (TF-TAVI), and 1,395 who had either a trans-apical or an unspecified approach. 
Table 1 Study characteristics

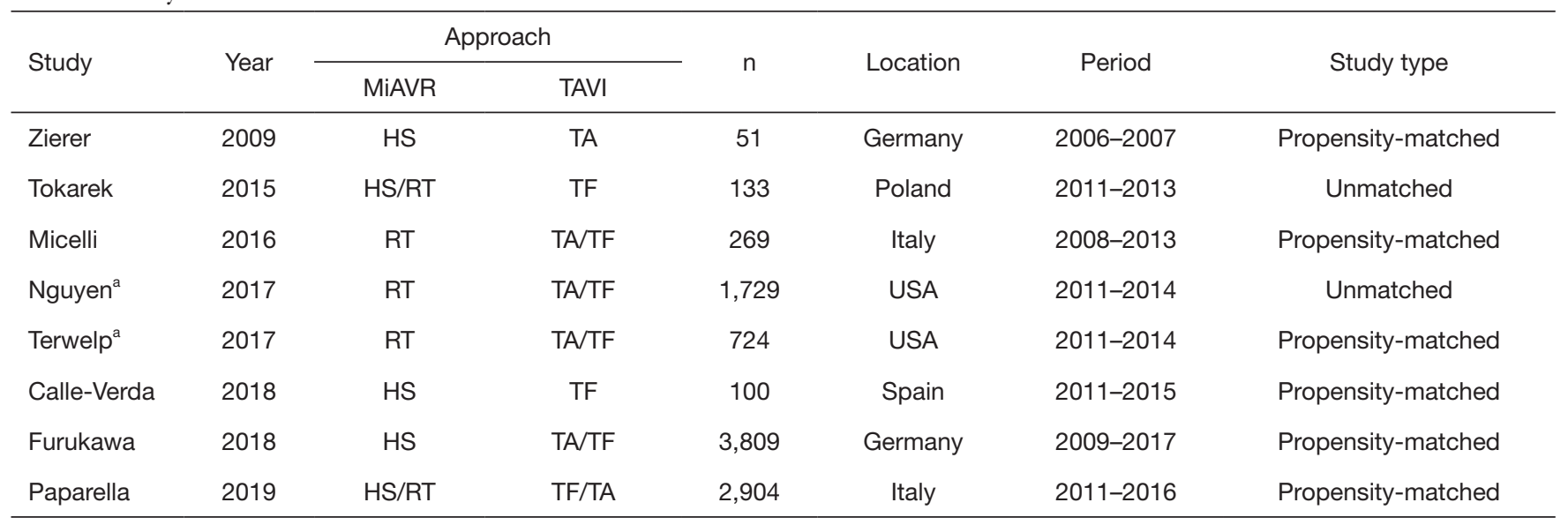

${ }^{a}$, same patient series. MiAVR, minimally invasive aortic valve replacement; TAVI, transcatheter aortic valve implantation; HS, hemi sternotomy; $\mathrm{RT}$, right anterior thoracotomy; TA, trans apical; TF, trans femoral.

\section{Baseline characteristics—pooled analysis}

Of the 9,744 total patients, $47.9 \%$ were female, (TAVI 49.2\%, MiAVR 46.1\%). Compared to MiAVR, TAVI patients were significantly older $(81.6 \pm 6.7$ vs. $71.4 \pm$ 10.8 years, $\mathrm{P}<0.001)$, significantly more likely to have $\mathrm{New}$ York Heart Association (NYHA) Class III/IV symptoms $(72.2 \%$ vs. $36.9 \%, \mathrm{P}<0.001)$ and had significantly lower left ventricular ejection fraction (LVEF) $(53.6 \pm 11.1 \mathrm{vs}$. $59.7 \pm 8.0 \%, \mathrm{P}<0.001)$. Preoperative patient characteristics from all studies are detailed in Table 2.

\section{Outcomes analysis}

After exclusion of non-matched studies, 2,252 patients from six studies were included in a meta-analysis of propensitymatched, post-operative outcomes.

\section{Mortality}

There was no significant difference in short term postoperative mortality, from the commencement of the procedure up to 30 days, between MiAVR and TAVI (2.5\% vs. $2.7 \%$, RR 0.99, 95\% CI, 0.58-1.70, $\mathrm{P}=0.97$ ) (Figure 3).

\section{Perioperative/procedural details}

Both rapid deployment and conventional stented bioprosthesis were used in MiAVR, with mechanical valves (Carbomedic, Bicarbon, LivoNova, London, UK) included in one study (23). Trans-catheter valves included Corevalve
(Medtronic, Minneapolis, MN, USA) and both older and newer generation SAPIEN valves (Edwards Lifescience, Irvine, CA, USA). The Lotus Valve System (Boston Scientific, MN, USA) was used in a small number of cases in one study (23) $(n=33)$. Valve choice was unspecified in three studies $(16,20,22)$.

Mean gradient following valve implantation did not differ between the two groups (mean difference $0.29 \mathrm{mmHg}, 95 \%$ $\mathrm{CI},-1.71$ to $2.3, \mathrm{P}=0.77, \mathrm{I}^{2}=81 \%$ ). There was no significant difference in ICU LOS (mean difference 0.71 days, $95 \%$ CI, -0.09 to $1.51, \mathrm{P}=0.08$ ), while total hospital LOS was shorter in TAVI compared to MiAVR (mean difference 2.77 days, 95\% CI, 0.99-4.55, $\mathrm{P}<0.01$ ) however heterogeneity was high in both $\left(\mathrm{I}^{2}=90 \%\right.$ and $95 \%$ respectively). Perioperative and procedural details are outlined in Table 3.

\section{Postoperative outcomes}

There was no statistical difference in postoperative stroke (0.8 vs. $1.7 \%$, OR $0.58,95 \%$ CI, $0.19-1.83, \mathrm{P}=0.36$ ), conversion to sternotomy (OR $0.50,95 \%$ CI, 0.14-1.80, $\mathrm{P}=0.29)$ or major bleeding ( $2.3 \%$ vs. $1.3 \%$, OR $1.64,95 \%$ CI, 0.73-3.67, $\mathrm{P}=0.23$ ) between MiAVR and TAVI (Figure 4). The requirement for PPM insertion was significantly higher in patients undergoing TAVI compared to MiAVR (17.6\% vs. $3.5 \%$, OR 0.21, 95\% CI, 0.09-0.51, $\mathrm{P}<0.01$ ). Postoperative AI or paravalvular leak (PVL) of at least moderate severity was also significantly higher in TAVI than MiAVR (10.6\% vs. $0.3 \%$, OR 0.05, 95\% CI, 0.01-0.20, $\mathrm{P}<0.01$ ). Acute kidney injury (AKI) was higher in MiAVR compared to TAVI (13.2\% vs. $4.5 \%$, OR 3.15, $95 \%$ CI, 


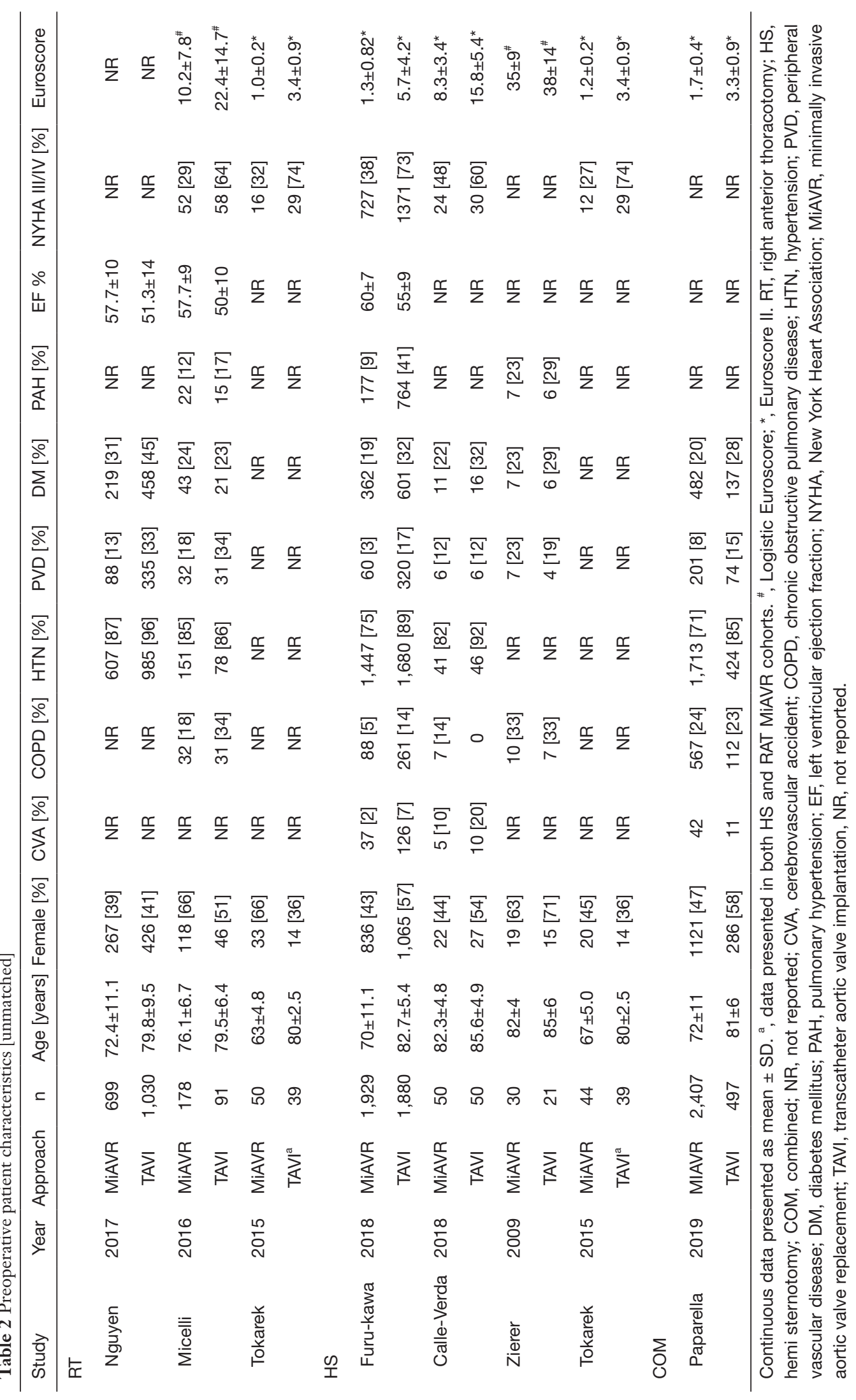




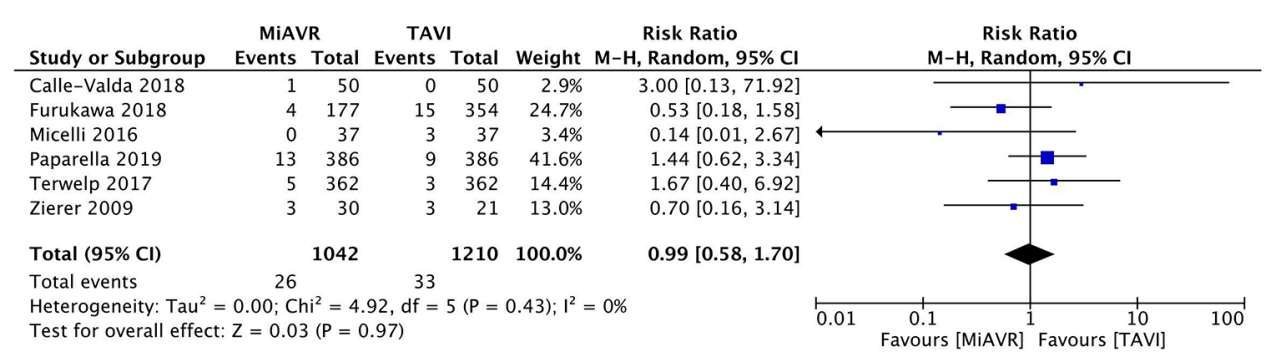

Figure 3 Forest plot of the risk ratio of overall mortality in matched patients undergoing MIAVR and TAVI. MiAVR, minimally invasive aortic valve replacement; TAVI, transcatheter aortic valve implantation; M-H, Mantel-Haenszel; CI, confidence interval. The estimate of the RR of each study corresponds to the middle of the squares, and the horizontal line shows the $95 \%$ CI. For each subgroup, the sum of the statistics, along with the summary RR, is represented by the middle of the solid diamonds. A test of heterogeneity between the trials within a subgroup is given below the summary statistics.

Table 3 Perioperative outcomes (propensity-matched)

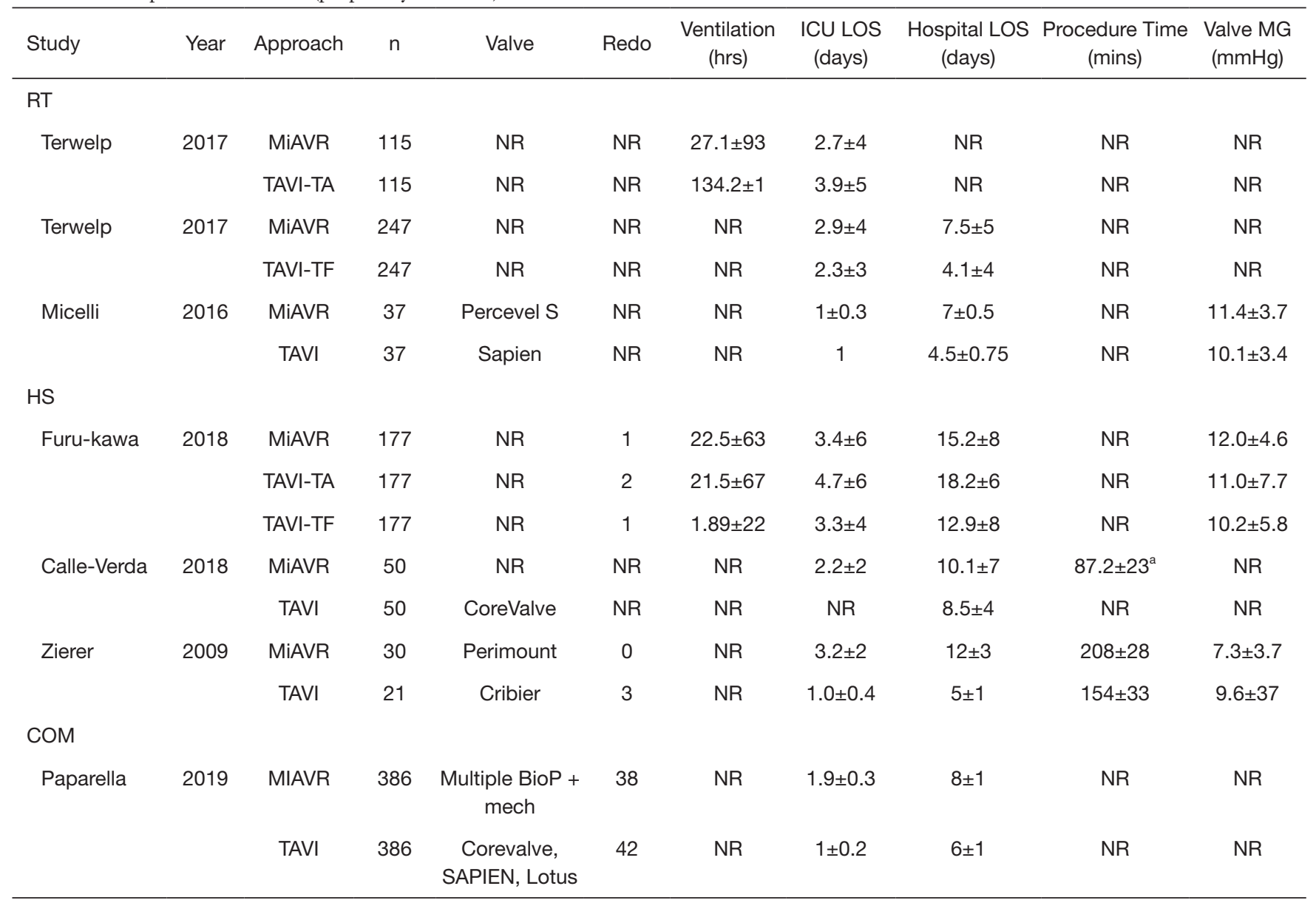

Continuous data presented as mean $\pm \mathrm{SD}$. ${ }^{\text {, }}$, cardiopulmonary bypass time. RT, right anterior thoracotomy; HS, hemi-sternotomy; COM, combined; NR, not reported; Redo, previous sternotomy; ICU, intensive care unit; LOS, length of stay; MG, mean gradient; MiAVR, minimally invasive aortic valve replacement; TAVI-TA, transcatheter aortic valve implantation via trans-apical approach; TAVI-TF, transcatheter aortic valve implantation via trans-femoral approach; BioP, bioprosthetic: mech-mechanical. 
A

\begin{tabular}{|c|c|c|c|c|c|c|c|c|c|c|}
\hline Study or Subgroup & $\begin{array}{c}\text { MiAV } \\
\text { Events }\end{array}$ & $\begin{array}{l}\text { /R } \\
\text { Total }\end{array}$ & $\begin{array}{l}\text { TAV } \\
\text { Events }\end{array}$ & 'Total & Weight & $\begin{array}{l}\text { Odds Ratio } \\
\text { M-H, Random, } 95 \% \mathrm{CI}\end{array}$ & & $\begin{array}{r}\text { Odds } \\
M-\mathrm{H}, \text { Rand } \\
\end{array}$ & $\begin{array}{l}\text { Ratio } \\
\text { lom, } 95 \% \mathrm{Cl}\end{array}$ & \\
\hline Calle-Valda 2018 & 1 & 50 & 2 & 50 & 15.98 & $0.49[0.04,5.58]$ & & & & \\
\hline Furukawa 2018 & 2 & 177 & 4 & 354 & $25.0 \%$ & $1.00[0.18,5.51]$ & & & & \\
\hline Micelli 2016 & 0 & 37 & 3 & 37 & $11.5 \%$ & $0.13[0.01,2.64]$ & & & & \\
\hline Paparella 2019 & 3 & 386 & 1 & 386 & $17.5 \%$ & $3.02[0.31,29.12]$ & & & & \\
\hline Terwelp 2017 & 1 & 362 & 10 & 362 & $19.9 \%$ & $0.10[0.01,0.77]$ & & & & \\
\hline Zierer 2009 & 1 & 30 & 0 & 21 & $10.1 \%$ & $2.19[0.08,56.30]$ & & & & \\
\hline Total $(95 \% \mathrm{Cl})$ & & 1042 & & 1210 & $100.0 \%$ & $0.58[0.19,1.83]$ & & & & \\
\hline Total events & 8 & & 20 & & & & & & & \\
\hline \multicolumn{7}{|c|}{$\begin{array}{l}\text { Heterogeneity: } \operatorname{Tau}^{2}=0.60 ; \mathrm{Chi}^{2}=7.12, \mathrm{df}=5(\mathrm{P}=0.21) ; \mathrm{I}^{2}=30 \% \\
\text { Test for overall effect: } \mathrm{Z}=0.92(\mathrm{P}=0.36)\end{array}$} & 0.01 & $\begin{array}{c}0.1 \\
\text { Favours [MiAVR] }\end{array}$ & 1 Favours [TAV]] & 100 \\
\hline
\end{tabular}

B

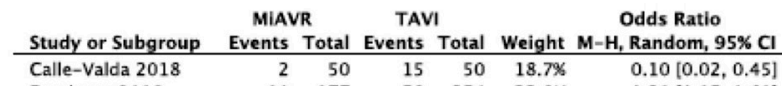
$\begin{array}{lllllll}\text { Furukawa } 2018 & 10 & 177 & 58 & 354 & 33.8 \% & 0.31[0.15,0.61]\end{array}$ $\begin{array}{lllllll}\text { Micelli } 2016 & 2 & 37 & 0 & 37 & 7.0 \% & 5.28[0.24,113.87]\end{array}$ $\begin{array}{lrrrrrr}\text { Paparella } 2019 & 10 & 386 & 75 & 386 & 34.2 \% & 0.11[0.06,0.22]\end{array}$ $\begin{array}{lrrrrrr}\text { Zierer } 2009 & 0 & 30 & 1 & 21 & 6.4 \% & 0.22[0.01,5.77]\end{array}$ $\begin{array}{lllll}\text { Total }(95 \% \mathrm{Cl}) & 680 & 848 & 100.0 \% & 0.21[0.09,0.51]\end{array}$ Total events $\quad 24 \quad 149 \quad 680 \quad 0.210 .09,0.51]$ Heterogeneity: $\mathrm{Tau}^{2}=0.48 ; \mathrm{Ch}^{2}=9.50, \mathrm{df}=4(\mathrm{P}=0.05) ; \mathrm{I}^{2}=58 \%$ Test for overall effect: $Z=3.46(P=0,0005)$

C

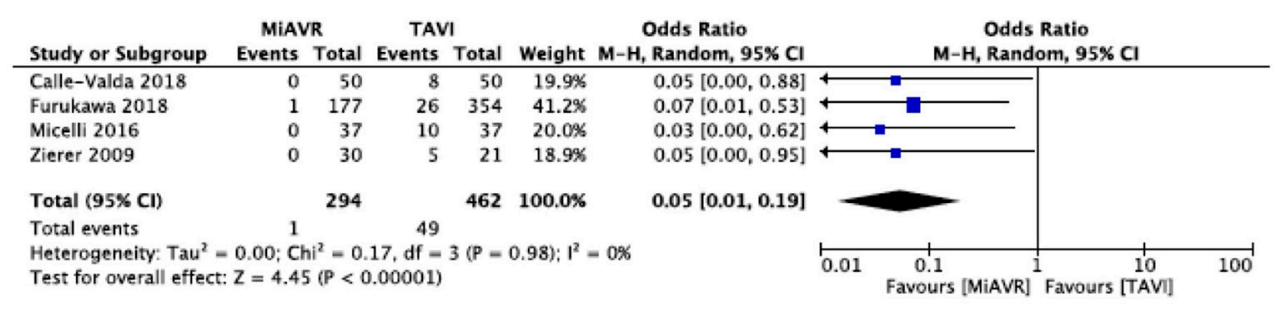

D

\begin{tabular}{|c|c|c|c|c|c|c|c|c|}
\hline \multirow{2}{*}{$\begin{array}{l}\text { Study or Subgroup } \\
\text { Calle-Valda } 2018\end{array}$} & \multicolumn{2}{|c|}{ MiAVR } & \multicolumn{2}{|c|}{ TAVI } & Weight & \multirow{2}{*}{$\begin{array}{c}\text { Odds Ratio } \\
\text { M-H, Random, } 95 \% \mathrm{Cl} \\
3.06[0.12,76.95]\end{array}$} & \multicolumn{2}{|c|}{$\begin{array}{c}\text { Odds Ratio } \\
\text { M-H, Random, } 95 \% \mathrm{Cl}\end{array}$} \\
\hline & 1 & 50 & 0 & 50 & $31.6 \%$ & & & 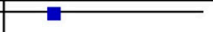 \\
\hline Micelli 2016 & 0 & 37 & 2 & 37 & $34.4 \%$ & $0.19[0.01,4.08]$ & & \\
\hline Zierer 2009 & 0 & 30 & 2 & 21 & $34.0 \%$ & $0.13[0.01,2.81]$ & & \\
\hline Total $(95 \% \mathrm{Cl})$ & & 117 & & 108 & $100.0 \%$ & $0.40[0.06,2.74]$ & & \\
\hline Total events & 1 & & 4 & & & & & \\
\hline $\begin{array}{l}\text { Heterogeneity: Tau } \\
\text { Test for overall effec }\end{array}$ & $\begin{array}{l}0.36 ; C h \\
Z=0.93\end{array}$ & $\begin{array}{l}i^{2}=2 . \\
(P=0\end{array}$ & $\begin{array}{l}28, \mathrm{df}= \\
0.35)\end{array}$ & $2(\mathbb{P}=$ & $0.32): 1^{2}$ & $=12 \%$ & $\begin{array}{lc}0.01 & 0.1 \\
& \text { Favours [MiAVR] }\end{array}$ & 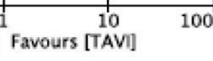 \\
\hline
\end{tabular}

E

$\begin{array}{cccc}\text { MiAVR } & \text { TAVI } & \text { Odds Ratio } \\ \text { Study or Subgroup } & \text { Events Total } & \text { Events Total }\end{array}$

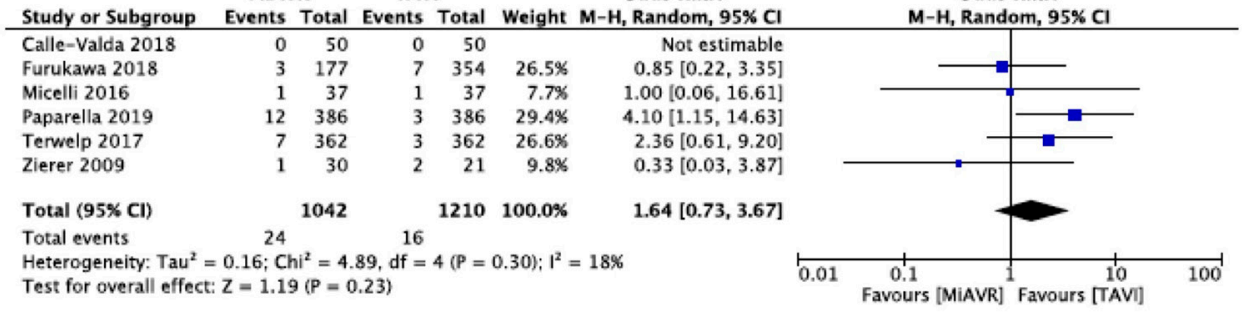

$\mathrm{F}$

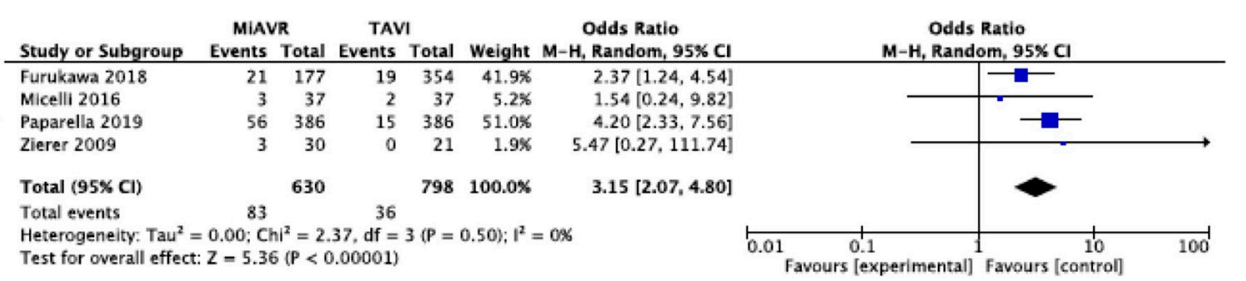

Figure 4 Perioperative outcomes. Forest plots of the odds ratio for matched patients of (A) stroke, (B) PPM insertion, (C) PVL/AI, (D) conversion to sternotomy, (E) major bleeding, (F) AKI. MiAVR, minimally invasive aortic valve replacement; TAVI, transcatheter aortic valve implantation; $\mathrm{M}-\mathrm{H}$, Mantel-Haenszel; CI, confidence interval. The estimate of the OR of each study corresponds to the middle of the squares, and the horizontal line shows the $95 \%$ CI. For each subgroup, the sum of the statistics, along with the summary OR, is represented by the middle of the solid diamonds. A test of heterogeneity between the trials within a subgroup is given below the summary statistics. 
Table 4 Postoperative outcomes (propensity-matched)

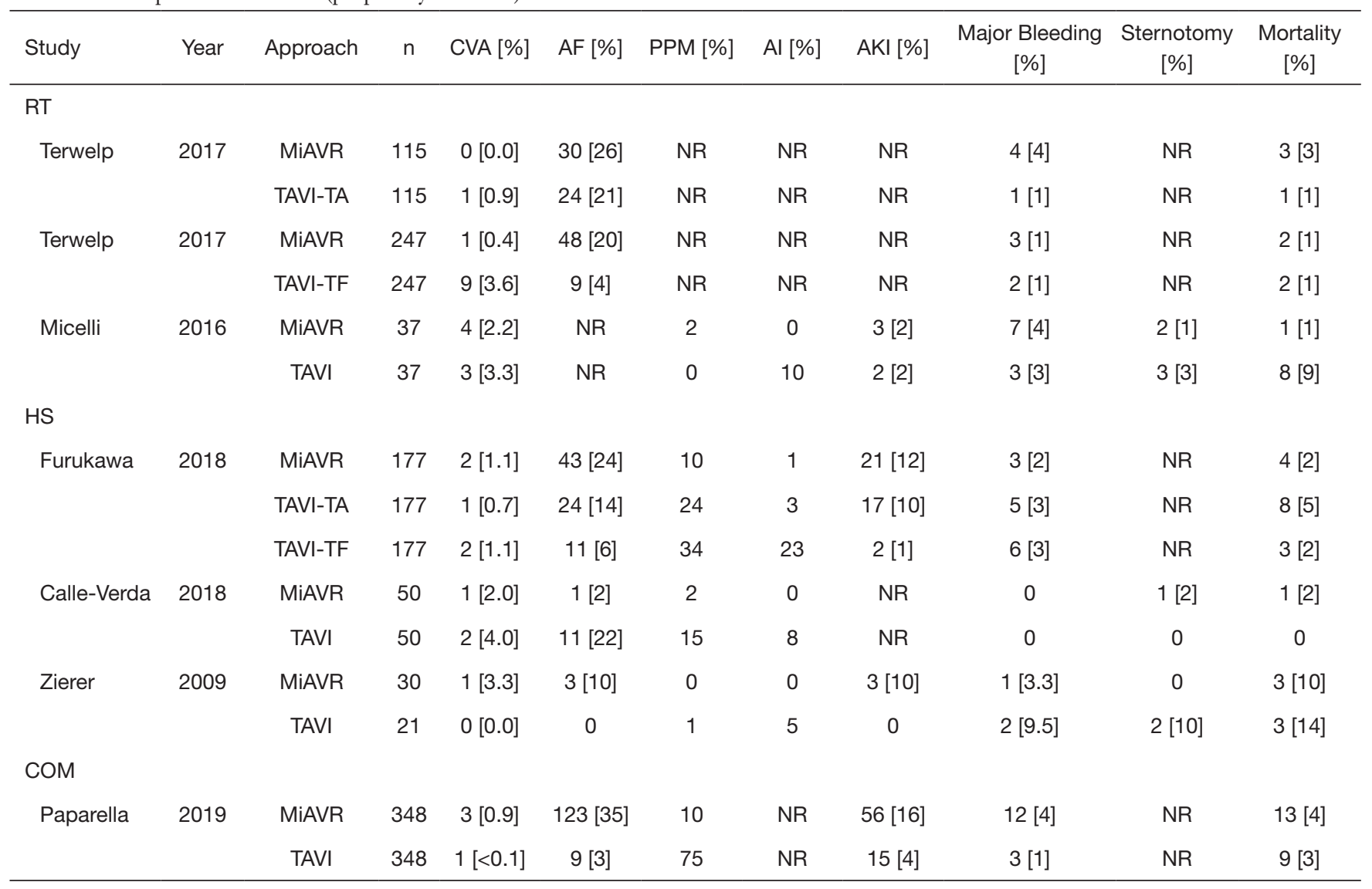

Continuous data presented as mean \pm SD. RT, right anterior thoracotomy; HS, hemi-sternotomy; COM, combined; NR, not reported; CVA, cerebrovascular accident; AF, atrial fibrillation; PPM, permanent pacemaker; Al, aortic insufficiency; AKI, acute kidney injury; MiAVR, minimally invasive aortic valve replacement; TAVI, transcatheter aortic valve implantation; TAVI-TF, transfemoral TAVI; TAVI-TA, transapical TAVI.

2.07-4.80, $\mathrm{P}<0.01$ ) (Figure 2). Post-procedural AF was greater in MiAVR compared to TAVI (OR 2.91, 95\% CI, 0.95-8.87, $\mathrm{P}=0.06$ ), however statistical significance was not reached and there was high heterogeneity between the studies $\left(\mathrm{I}^{2}=90 \%\right)$. Postoperative outcomes are detailed in Table 4.

\section{MiAVR and TF-TAVI}

Comparing propensity-matched patients undergoing TAVI via the transfemoral route (TF-TAVI) and MiAVR resulted in 1,081 patients from 4 studies being included for subanalysis $(16,17,20,24)$. There was no significant difference in mortality (RR 0.9, 95\% CI, 0.35-2.25, P=0.82) between MiAVR and TF-TAVI. A signal towards a reduction in stroke was seen in MiAVR, however this did not reach significance (OR 0.34, 95\% CI, 0.1-1.1, P=0.07). Rates of post-procedural AI/PVL and PPM requirement were significantly lower in patients undergoing MiAVR compared to TF-TAVI (AI/PVL $0.3 \%$ vs. $12 \%$, OR $0.05,95 \% \mathrm{CI}$, 0.01-0.23, $\mathrm{P}<0.001$; PPM 3.8 vs. 19.9\%, OR 0.18, 95\% CI, $0.08-0.39, \mathrm{P}<0.01)$. There was insufficient data to analyse other outcomes. This sub-analysis is summarised in Figure 5.

\section{Discussion}

The results of this meta-analysis suggest that early mortality is similar between MiAVR and TAVI in appropriately selected, surgical risk-matched patients. The requirement for a PPM and post-procedural AI was lower in MiAVR than TAVI, with a trend towards lower stroke in MiAVR patients compared to TF-TAVI. Lower rates of POAF and AKI were seen in TAVI compared to MiAVR. These results should however be considered within both their clinical context and the limitations of this review.

Short term mortality did not differ between MiAVR and 


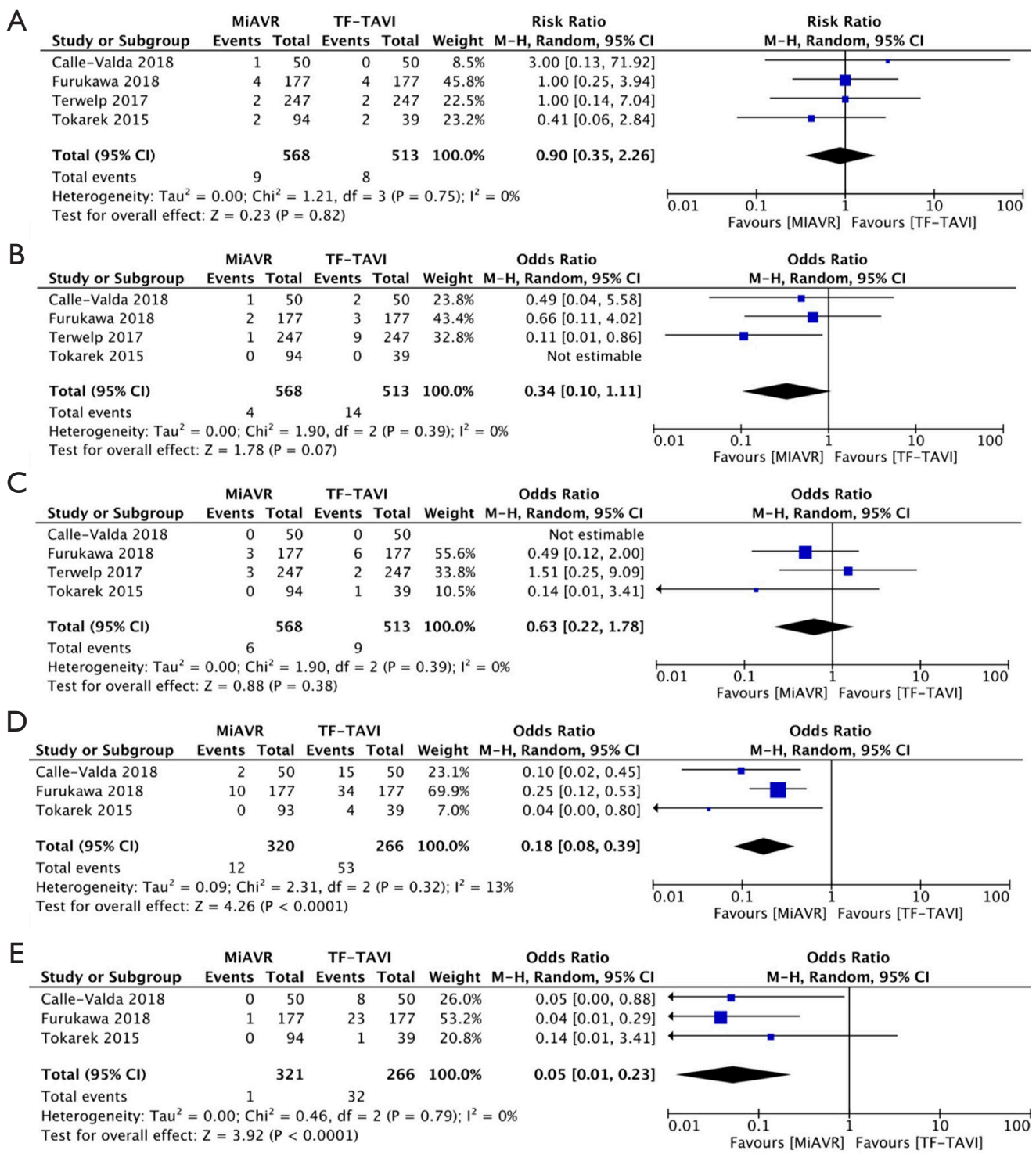

Figure 5 Forest plot of the risk ratio of overall mortality in matched patients undergoing MIAVR and TAVI-TF (A), the odds ratio for matched patients for CVA insertion (B), major bleeding (C), PPM insertion (D) and PVL/AI (E). MiAVR, minimally invasive aortic valve replacement; TAVI-TF, transcatheter aortic valve implantation via trans-femoral route; M-H, Mantel-Haenszel; CI, confidence interval. The estimate of the RR or OR of each study corresponds to the middle of the squares, and the horizontal line shows the $95 \%$ CI. For each subgroup, the sum of the statistics, along with the summary RR or OR, is represented by the middle of the solid diamonds. A test of heterogeneity between the trials within a subgroup is given below the summary statistics.

TAVI. Large randomized trials comparing TAVI to SAVR have similarly demonstrated no difference in mortality out to 5 years $(7,9)$. In our analysis, there was a signal towards a reduction in stroke rate in MiAVR patients, which strengthened when only trans-femoral access was included for TAVI. Preoperative CT-imaging of the aorta may be performed prior to MiAVR to identify the relational anatomy and orientation of the aortic valve, aortic root and ascending aorta. TAVI requires detailed imaging of access vasculature and similar proximal aortic structures. The low stroke rate observed in both cohorts in our analysis may represent the detection of prohibitive features such as aortic calcium, identified from preoperative imaging, seeing these patients appropriately treated with alternative 
methods. The incidence of stroke following SAVR and TAVI varies substantially across the remaining observational and non-randomised literature. Cumulative stroke rates in non-comparative studies after TAVI at 30 days, one year and over five years (where data is available) ranges from $2.5-4.0 \%, 3.6-6.1 \%$ and $5.9-10.6 \%$ respectively $(12,25-28)$. There is a paucity of dedicated studies examining stroke rate following isolated SAVR and MiAVR, but in those studies identified with moderate-to-high risk patients, the rates of stroke at 30 days out to five years ranges from $1.9-5.4 \%$ (29-31). These ranges may reflect several factors; the heterogeneity of patient inclusion, variations in surgical and procedural techniques, variation in diagnostic criteria for stroke following these procedures and the limitations of observational studies. Many studies lack clear stroke diagnostic criteria, particularly in regard to the requirement of radiologic imaging for diagnostic confirmation. The studies included in our analysis do not specifically outline parameters for stroke diagnosis, however the analysis of only propensity-matched data allows a uniform diagnostic assessment applied across both TAVI and MiAVR cohorts.

A major limitation of TAVI has been the rates of postprocedural AI or PVL. Nonetheless, rates of moderate to severe AI in TAVI range from $5-20 \%$ depending on the prosthesis implanted (9,32-34). The AI rates of TAVI patients included in our analysis were within this range. The rate of AI following MiAVR was exceptionally low, as should be expected following surgical valve implantation. Higher rates of AI after TAVI are associated with increased mortality, which may include only mild AI $(33,34)$. Mechanisms for this are still being investigated, but may be due to retained calcified aortic leaflets, which can create an irregular annulus in which transcatheter valves are deployed. Design features of current generation transcatheter valves have attempted to overcome this issue by modifying valve design to be repositionable or include features such as a sealing cuff or anti-leak skirt (35). The development of catheter-based leak-closure devices and other strategies such as post-deployment balloon expansion have also ensued $(36,37)$. Rates of AI have remained, however, between $2.2-10.3 \%$ (38-42). The use of a sutureless prosthesis via a surgical approach has not resulted in an increased incidence of postoperative AI, with rates remaining under 1\% (43). The ability to surgically resect the diseased valve leaflets and decalcify the aortic annulus prior to insertion of a prosthetic valve may be a critical factor in ensuring low rates of AI.

Requirement for new PPM was significantly higher after TAVI than MiAVR. The rates of new PPM insertion after TAVI in the studies included in our analysis falls within other published rates, which range from $8 \%$ to $40 \%$ (7,9,32). Published rates for new PPM after surgical AVR is significantly lower than TAVI in most trials, ranging from $2.0 \%$ to $11.8 \%$, including studies examining matched highrisk patients (44-46). Large registry data has demonstrated reduced all-cause long-term survival in patients requiring PPM after SAVR and this decreased survival is also apparent in shorter-term follow up of TAVI patients (47). Sutureless and rapid-deployment bioprosthesis are an alternative to traditional stented surgical valves requiring annular suturing for securement. Sutureless valves have reported higher rates of postoperative PPM requirement compared to valves requiring annular suturing, however this incidence still remains significantly lower than TAVI $(48,49)$.

A reduction in AKI, POAF and overall hospital LOS are outcomes repeatedly shown to be in favour of TAVI when compared with SAVR $(7,9,32)$. These outcomes are strong drivers for TAVI advocates, with AKI and POAF contributing to increased LOS as well as increased shortand long-term mortality after AVR (50,51). Our analysis showed a significant reduction in AKI in favour of TAVI however further follow up analysis is required to delineate the prognostic significance of this result, as transient AKI may not predict poorer outcome (52). No long-term data is currently available for the studies included in our analysis. Our analysis also found a significant reduction in hospital LOS in favour of TAVI. The overall mean difference in hospital LOS was 0.2 days, however the clinical relevance of this is uncertain. Furthermore, we found no difference in rates of POAF although the trend was in favour of TAVI. There was high heterogeneity in the analysis of both outcomes (POAF $\mathrm{I}^{2}=76 \%$, LOS $\left.\mathrm{I}^{2}=95\right)$, thereby confounding the significance and applicability of these results. This heterogeneity is driven by a small study with 50 patients in each cohort, reporting a POAF rate of just $2 \%$ in MiAVR patients, compared to $22 \%$ of TAVI patients (17). Likewise, heterogeneity for LOS is derived from a single study showing TAVI mean LOS $4 \pm 5.4$ days compared to 3.4 \pm 5.9 days for MiAVR (16). This study had equal numbers of TA and TF-TAVI patients included in the analysis.

\section{Study limitations}

Limitations of this study include the retrospective nature of the included studies and the potential patient selection bias that ensues. Additionally, patients undergoing TA-TAVI makes up nearly one third of all TAVI patients included in 
our analysis. The trans-apical approach is well established as having a higher rate of complications $(53,54)$ and in modern day practice the trans-apical approach contributes only a small portion of total TAVI caseloads. We considered it prudent to include tall-access approaches to TAVI in our analysis due to propensity-matching being performed and outcomes reported as risk-matched data. Supplementary analysis of MiAVR and TF-TAVI showed similar results to the primary analysis, suggesting the results may be applicable to a greater TF-TAVI cohort. Valve technology for both TAVI and SAVR has evolved significantly over the timeframe of this analysis and many included studies did not report numbers of valve type used.

Finally, as already highlighted, stroke reporting was not well defined in any of the included studies. The inclusion of only propensity-matched data into the analysis reduces the impact of all above mentioned limitations and a random-effects model for the meta-analysis was chosen to further account for these limitations. However, the effect of unregistered covariates on the clinical outcomes cannot be completely accounted for.

\section{Conclusions}

Notwithstanding the limitations of this study, MiAVR and TAVI provide equivalent short-term mortality for appropriately-selected patients with severe AS, with MiAVR demonstrating lower rates of postoperative PPM, AI and a trend towards lower stroke rates. The use of minimallyinvasive approaches to AVR may be considered as a feasible alternative to TAVI and may be discussed as a separate entity to SAVR via full sternotomy when deciding the most optimal approach for valve replacement in patients with AS. High-quality prospective trials are needed in order to further evaluate these results.

\section{Acknowledgments}

Funding: None.

\section{Footnote}

Reporting Checklist: The authors have completed the PRISMA reporting checklist. Available at http://dx.doi. org/10.21037/jtd-20-2233

Conflicts of Interest: All authors have completed the ICMJE uniform disclosure form (available at http://dx.doi. org/10.21037/jtd-20-2233). Dr. MN reports being an unpaid advisor and proctor for Edwards Lifesciences transcatheter aortic valve replacement. The other authors have no conflicts of interest to declare.

Ethical Statement: The authors are accountable for all aspects of the work in ensuring that questions related to the accuracy or integrity of any part of the work are appropriately investigated and resolved.

Open Access Statement: This is an Open Access article distributed in accordance with the Creative Commons Attribution-NonCommercial-NoDerivs 4.0 International License (CC BY-NC-ND 4.0), which permits the noncommercial replication and distribution of the article with the strict proviso that no changes or edits are made and the original work is properly cited (including links to both the formal publication through the relevant DOI and the license). See: https://creativecommons.org/licenses/by-nc-nd/4.0/.

\section{References}

1. Carabello BA. Introduction to Aortic Stenosis. Circ Res 2013;113:179-85.

2. Glauber M, Miceli A, Gilmanov D, et al. Right anterior minithoracotomy versus conventional aortic valve replacement: a propensity score matched study. J Thorac Cardiovasc Surg 2013;145:1222-6.

3. Bonacchi M, Prifti E, Giunti G, et al. Does ministernotomy improve postoperative outcome in aortic valve operation? A prospective randomized study. Ann Thorac Surg 2002;73:460-5.

4. Ghanta RK, Lapar DJ, Kern JA, et al. Minimally invasive aortic valve replacement provides equivalent outcomes at reduced cost compared with conventional aortic valve replacement: A real-world multi-institutional analysis. J Thorac Cardiovasc Surg 2015;149:1060-5.

5. Bowdish ME, Hui DS, Cleveland JD, et al. A comparison of aortic valve replacement via an anterior right minithoracotomy with standard sternotomy: a propensity score analysis of 492 patients. Eur J Cardiothorac Surg 2016;49:456-63.

6. Fudulu D, Lewis $\mathrm{H}$, Benedetto U, et al. Minimally invasive aortic valve replacement in high risk patient groups. J Thorac Dis 2017;9:1672-96.

7. Reardon MJ, Van Mieghem NM, Popma JJ, et al. Surgical or Transcatheter Aortic-Valve Replacement in IntermediateRisk Patients. N Engl J Med 2017;376:1321-31.

8. Mack MJ, Leon MB, Smith CR, et al. 5-year outcomes of transcatheter aortic valve replacement or surgical aortic 
valve replacement for high surgical risk patients with aortic stenosis (PARTNER 1): a randomised controlled trial. Lancet 2015;385:2477-84.

9. Leon MB, Smith CR, Mack MJ, et al. Transcatheter or Surgical Aortic-Valve Replacement in Intermediate-Risk Patients. N Engl J Med 2016;374:1609-20.

10. Mack MJ, Leon MB, Thourani VH, et al. Transcatheter Aortic-Valve Replacement with a Balloon-Expandable Valve in Low-Risk Patients. N Engl J Med 2019;380:1695-705.

11. Popma JJ, Deeb GM, Yakubov SJ, et al. Transcatheter Aortic-Valve Replacement with a Self-Expanding Valve in Low-Risk Patients. N Engl J Med 2019;380:1706-15.

12. Chakos A, Wilson-Smith A, Arora S, et al. Long term outcomes of transcatheter aortic valve implantation (TAVI): a systematic review of 5 -year survival and beyond. Ann Cardiothorac Surg 2017;6:432-43.

13. Castrovinci S, Emmanuel S, Moscarelli M, et al. Minimally invasive aortic valve surgery. J Geriatr Cardiol 2016;13:499-503.

14. Stroup DF, Berlin JA, Morton SC, et al. Meta-analysis of Observational Studies in Epidemiology: A Proposal for Reporting. JAMA 2000;283:2008-12.

15. Moher D, Liberati A, TetzlaffJ, et al. for the PRISMA Group. Preferred reporting items for systematic reviews and metaanalyses: the PRISMA statement. BMJ 2009;339:b2535.

16. Furukawa N, Kuss O, Emmel E, et al. Minimally invasive versus transapical versus transfemoral aortic valve implantation: A one-to-one-to-one propensity score-matched analysis. J Thorac Cardiovasc Surg 2018;156:1825-34.

17. Calle-Valda CM, Aguilar R, Benedicto A, et al. Outcomes of Aortic Valve Replacement According to Surgical Approach in Intermediate and Low Risk Patients: A Propensity Score Analysis. Heart Lung Circ 2018;27:885-92.

18. Miceli A, Gilmanov D, Murzi M, et al. Minimally invasive aortic valve replacement with a sutureless valve through a right anterior mini-thoracotomy versus transcatheter aortic valve implantation in high-risk patients. Eur J Cardiothorac Surg 2016;49:960-5.

19. Tokarek T, Sobczyński R, Dziewierz A, et al. Clinical outcomes in patients after surgical and transcatheter aortic valve replacement. Pol Arch Med Wewn 2015;125:755-64.

20. Terwelp MD, Thourani VH, Zhao Y, et al. Minimally Invasive Versus Transcatheter and Surgical Aortic Valve Replacement: A Propensity Matched Study. J Heart Valve Dis 2017;26:146-54.

21. Zierer A, Wimmer-Greinecker G, Martens S, et al. Is transapical aortic valve implantation really less invasive than minimally invasive aortic valve replacement? J Thorac
Cardiovasc Surg 2009;138:1067-72.

22. Nguyen TC, Terwelp MD, Thourani VH, et al. Clinical trends in surgical, minimally invasive and transcatheter aortic valve replacement†. Eur J Cardiothorac Surg 2017;51:1086-92.

23. Paparella D, Santarpino G, Malvindi PG, et al. Minimally invasive surgical versus transcatheter aortic valve replacement: A multicenter study. Int J Cardiol Heart Vasc 2019;23:100362.

24. Tokarek T, Siudak Z, Dziewierz A, et al. Assessment of quality of life in patients after surgical and transcatheter aortic valve replacement. Catheter Cardiovasc Interv 2016;88:E80-8.

25. Barbanti M, Petronio AS, ettori F, et al. 5-Year Outcomes After Transcatheter Aortic Valve Implantation With CoreValve Prosthesis. JACC Cardiovasc Interv 2015;8:1084-91.

26. Gerckens U, Tamburino C, Bleiziffer S, et al. Final 5-year clinical and echocardiographic results for treatment of severe aortic stenosis with a self-expanding bioprosthesis from the ADVANCE Study. Eur Heart J 2017;38:2729-38.

27. Zahn R, Werner N, Gerckens U, et al. Five-year followup after transcatheter aortic valve implantation for symptomatic aortic stenosis. Heart 2017;103:1970-6.

28. Duncan A, Ludman P, Banya W, et al. Long-term outcomes after transcatheter aortic valve replacement in high-risk patients with severe aortic stenosis: the U.K. Transcatheter Aortic Valve Implantation Registry. JACC Cardiovasc Interv 2015;8:645-53.

29. Subramanian S, Rastan AJ, Holzhey D, et al. Conventional aortic valve replacement in transcatheter aortic valve implantation candidates: a 5-year experience. Ann Thorac Surg 2012;94:726-9.

30. Okamoto Y, Yamamoto K, Yoshii S. Early and Late Outcomes of Aortic Valve Replacement Using Bioprosthetic Versus Mechanical Valve in Elderly Patients: A Propensity Analysis. J Card Surg 2016;31:195-202.

31. Idrees JJ, Schiltz NK, Johnston DR, et al. Trends, Predictors, and Outcomes of Stroke After Surgical Aortic Valve Replacement in the United States. Ann Thorac Surg 2016;101:927-35.

32. Søndergaard L, Steinbrüchel DA, Ihlemann N, et al. TwoYear Outcomes in Patients With Severe Aortic Valve Stenosis Randomized to Transcatheter Versus Surgical Aortic Valve Replacement: The All-Comers Nordic Aortic Valve Intervention Randomized Clinical Trial. Circ Cardiovasc Interv 2016;9:e003665.

33. Reardon MJ, Adams DH, Kleiman NS, et al. 2-Year Outcomes in Patients Undergoing Surgical or SelfExpanding Transcatheter Aortic Valve Replacement. J Am 
Coll Cardiol 2015;66:113-21.

34. Abdel-Wahab M, Zahn R, Horack M, et al. Aortic regurgitation after transcatheter aortic valve implantation: incidence and early outcome. Results from the German transcatheter aortic valve interventions registry. Heart 2011;97:899-906.

35. Pilgrim T, Lee JKT, O'Sullivan CJ, et al. Early versus newer generation devices for transcatheter aortic valve implantation in routine clinical practice: a propensity score matched analysis. Open Heart 2018;5:e000695-702.

36. Levisay JP, Salinger M, Feldman TE. Paravalvular leak closure after TAVR. Cardiac Interventions Today 2014:53-7.

37. Cruz-González I, Rama-Merchan JC, Rodríguez-Collado J, et al. Paravalvular Leak Closure After Transcatheter Aortic Valve Implantation Simultaneously Using Amplatzer ${ }^{\mathrm{TM}}$ Vascular Plug III and IV Devices. Rev Esp Cardiol 2015;68:1035-6.

38. Wendt D, Al-Rashid F, Kahlert P, et al. Low Incidence of Paravalvular Leakage With the Balloon-Expandable Sapien 3 Transcatheter Heart Valve. Ann Thorac Surg 2015;100:819-25; discussion 825-6.

39. Kodali S, Thourani VH, White J, et al. Early clinical and echocardiographic outcomes after SAPIEN 3 transcatheter aortic valve replacement in inoperable, high-risk and intermediate-risk patients with aortic stenosis. Eur Heart J 2016;37:2252-62.

40. Yoon SH, Sharma R, Chakravarty T, et al. Clinical outcomes and prognostic factors of transcatheter aortic valve implantation in bicuspid aortic valve patients. Ann Cardiothorac Surg 2017;6:463-72.

41. Pibarot P, Hahn RT, Weissman NJ, et al. Association of Paravalvular Regurgitation With 1-Year Outcomes After Transcatheter Aortic Valve Replacement With the SAPIEN 3 Valve. JAMA Cardiol 2017;2:1208-16.

42. Meyer A, Unbehaum A, Hammandi M, et al. Comparison of 1-Year Survival and Frequency of Paravalvular Leakage Using the Sapien 3 Versus the Sapien X'T for Transcatheter Aortic Valve Implantation for Aortic Stenosis. Am J Cardiol 2017;120:2247-55.

43. Wang N, Tsai YC, Niles N, et al. Transcatheter aortic valve implantation (TAVI) versus sutureless aortic valve replacement (SUAVR) for aortic stenosis: a systematic review and metaanalysis of matched studies. J Thorac Dis 2016;8:3283-93.

44. Van Mieghem NM, Head SJ, de Jong W, et al. Persistent annual permanent pacemaker implantation rate after surgical aortic valve replacement in patients with severe aortic stenosis. Ann Thorac Surg 2012;94:1143-9.
45. Baraki H, Ahmad Al A, Jeng-Singh S, et al. Pacemaker dependency after isolated aortic valve replacement: do conductance disorders recover over time? Interact Cardiovasc Thorac Surg 2013;16:476-81.

46. Siontis GCM, Praz F, Pilgrim T, et al. Transcatheter aortic valve implantation vs. surgical aortic valve replacement for treatment of severe aortic stenosis: a meta-analysis of randomized trials. Eur Heart J 2016;37:3503-12.

47. Nazif TM, Dizon JM, Hahn RT, et al. Predictors and clinical outcomes of permanent pacemaker implantation after transcatheter aortic valve replacement: the PARTNER (Placement of AoRtic TraNscathetER Valves) trial and registry. JACC Cardiovasc Interv 2015;8:60-9.

48. Muneretto C, Alfieri O, Cesana BM, et al. A comparison of conventional surgery, transcatheter aortic valve replacement, and sutureless valves in "'real-world"” patients with aortic stenosis and intermediate- to high-risk profile. J Thorac Cardiovasc Surg 2015;150:1570-7.

49. Repossini A, Fischlein T, Solinas M, et al. Stentless sutureless and transcatheter valves: a comparison of the hemodynamic performance of different prostheses concept. Minerva Cardioangiol 2018;66:180-90.

50. Filardo G, Hamilton C, Hamman B, et al. New-Onset Postoperative Atrial Fibrillation and Long-Term Survival After Aortic Valve Replacement Surgery. Ann Thorac Surg 2010;90:474-9.

51. O'Neal JB, Shaw AD, Billings FT. Acute kidney injury following cardiac surgery: current understanding and future directions. Crit Care 2016;20:187.

52. Borracci RA, Macias Miranda J, Ingino CA. Transient acute kidney injury after cardiac surgery does not independently affect postoperative outcomes. J Card Surg 2018;33:727-33.

53. Blackstone EH, Suri RM, Rajeswaran J, et al. PropensityMatched Comparisons of Clinical Outcomes After Transapical or Transfemoral Transcatheter Aortic Valve Replacement. Circulation 2015;131:1989-2000.

54. Muhammad S, Azzouz TMH, Akinapelli A, et al. Transfemoral Versus Trans-apical Access in Transcatheter Aortic Valve Implantation; A Meta-analysis. JACC Cardiovasc Interv 2016;9:S45-6.

Cite this article as: Doyle MP, Woldendorp $\mathrm{K}, \mathrm{Ng} \mathrm{M}$, Vallely MP, Wilson MK, Yan TD, Bannon PG. Minimallyinvasive versus transcatheter aortic valve implantation: systematic review with meta-analysis of propensity-matched studies. J Thorac Dis 2021;13(3):1671-1683. doi: 10.21037/jtd-202233 